\title{
PERSPECTIVES OF SPEECH-LANGUAGE PATHOLOGISTS ON THE USE OF TELEPRACTICE IN SCHOOLS: QUANTITATIVE SURVEY RESULTS
}

\author{
JANICE K. TUCKER, SLP.D. \\ Speech language Support Programs, Lincoln intermediate Unit \#12, New Oxford, PA
}

\section{ABSTRACT}

This research surveyed 170 school-based speech-language pathologists (SLPs) in one northeastern state, with only $1.8 \%$ reporting telepractice use in school-settings. These results were consistent with two ASHA surveys $(2002 ; 2011)$ that reported limited use of telepractice for school-based speech-language pathology. In the present study, willingness to use telepractice was inversely related to age, perhaps because younger members of the profession are more accustomed to using technology. Overall, respondents were concerned about the validity of assessments administered via telepractice; whether clinicians can adequately establish rapport with clients via telepractice; and if therapy conducted via telepractice can be as effective as in-person speech-language therapy. Most respondents indicated the need to establish procedures and guidelines for school-based telepractice programs.

Keywords: speech therapy, telepractice, schools

Telepractice is receiving increasing attention in the field of speech-language pathology (American Speech-Language-Hearing Association [ASHA], 2005c, 2010; Juenger, 2009a). ASHA conducted a survey of its membership in 2002 and found that only $11 \%$ of respondents were engaged in the use of telepractice, with lack of knowledge about telepractice emerging as the greatest barrier.

A membership survey conducted by ASHA in 2011 included two questions pertaining to telepractice. The 1455 respondents indicated a $2.3 \%$ utilization of delivery of any service via telepractice in speech-language pathology; for the school population this yielded an incidence rate of $1.6 \%$. The client populations included (presented from greatest to least served): children in homes, children or adults in satellite clinics/hospitals, children in schools, adults in home or work environments, and adults in military/VA.

The potential benefits of telepractice are substantial (ASHA 2005c, 2010; Houn \& Trottier, 2006; Mashima \& Doarn, 2008) and could include: greater access to speech-language pathology services for underserved populations (e.g., rural and inner city students); improved access to services for clients with cultural and linguistic diversity, (including those who require bilingual clinicians); individualized therapeutic programming; greater access to dysphagia experts; increased ease of collaboration among team members; and savings in travel time and costs for providers (ASHA, 2005c, 2010; Polovoy, 2008). Service delivery in public schools via telepractice could also support free and appropriate education for students and increase student learning (Juenger, 2009b).

However, much still needs to be learned about how speech-language pathologists view telepractice (ASHA, 2010; Hill et al., 2006; Torrens, 2004), especially in light of evidence that "'providers' perceptions are less than enthusiastic" (Whitten \& Holtz, 2008a, p. 952). An enhanced understanding of SLPs' perceptions concerning the use of telepractice in schools could help identify reasons for its limited adoption, and inform the development of a framework from which to build acceptance and confidence (ASHA 2010; Torrens, 2004; Whitten \& Holtz, 2008a, 2008b).

\section{METHODS}

\section{SURVEY CONSTRUCTION}

A web-based survey was constructed, based in part on the ASHA Telepractice Survey of 2002 for Audiologists, SLPs, and Speech, Language, and Hearing Researchers. The ASHA 2002 instrument consisted of closed-ended questions regarding the amount of use of telepractice, type of client services, settings, technologies, and reimbursement of telepractice services. This tool also surveyed the participants' education or training and reasons for utilizing telepractice (intervention or research purposes). 
With permission from ASHA, 11 out of 21 questions from the 2002 survey (Questions 1, 2, 5, 6, 7, 9, 10, 14, 15,16 , and 20) were used with revisions made for the purposes of this present study to reflect a school focus and SLP respondents, (as opposed to both SLPs and audiologists who informed the original 2002 survey). This present study's survey included two items pertaining to demographics of all respondents and 12 questions relating directly to specificity of the use of telepractice in school settings and the knowledge and skills of only those SLPs involved in telepractice. The subsequent 17 item section of this quantitative instrument incorporated the themes and comments that emerged from the qualitative interviews in the first phase of this mixed methods study and centered on all respondent SLPs' attitudes and beliefs with regard to the use of telepractice in speech-language pathology. Four remaining openended questions allowed SLPS' to list their reasons to use or not use telepractice and for any additional comments they wished to provide. The survey consisted of a total of 35 items and required less than 20 minutes to complete (Creswell, 2008). Approval to conduct the research was granted by the Institutional Review Board (IRB) of Nova Southeastern University.

\section{PILOT TESTING}

To provide a measure of internal clarity, content and construct validity, the revised ASHA Telepractice instrument was pretested via an email survey with 10 SLPs; each had more than 5 years of experience with school-based speech therapy in the target state (Creswell, 2008). The pilot group was asked to review the questions for ambiguity, terminology, and ease of administration. Minor adjustments were made to spelling and word order based upon their recommendations.

\section{SURVEY ADMINISTRATION}

The survey was placed in a password protected Google account, a web-based survey system and disseminated to the 1900 members of the state's speech-languagehearing association membership listserv. [The researcher did not have access to or knowledge of the membership's names or email addresses.] Each ASHA certified SLP received the quantitative data collection instrument, along with a Participation Letter and introductory email briefly explaining the purpose of the study, risks and benefits of participating, and information concerning confidentiality and the right to withdraw from the study. A reminder email was sent to the membership via the association's listserv two weeks later to encourage participants to respond (Creswell, 2008). Selection bias was limited by including the entire speech-language-hearing association membership of SLPs in the targeted state.

\section{PARTICIPANTS}

The quantitative survey was emailed to members of the state's speech-language-hearing association via that association's listserv of 1900 ASHA-certified SLPs. According to 2007-2008 statistics from the National Center for Education Statistics (NECS), the population of public school-based therapists certified to teach the speech and language impaired in the selected state consisted of over 3200 individuals (NECS, 2008). Therefore a subset of 1900 ASHA-certified SLPs in this state should provide representation of SLPs providing services in school settings and afford an adequate response rate (Creswell \& Plano Clark, 2011; Fink, 2003). Additionally, the association's listserv membership included those SLP professionals that provide telepractice services to charter or cyber schools. Online public cyber school enrollment in this northeastern state has increased approximately 760\% from 2001-2007 (Benefield \& Runk, 2008), and students with Individualized Educational Plans (IEPS) constitute $14 \%$ of the enrollment in these cyber schools (Müller, 2009). Telepractice in speech-language pathology may be utilized more in these school settings due to existing distance educational technologies, and as such, the viewpoints and data from SLPs providing the telepractice services to these educational environments were included in this study (Alverson et al., 2008; ASHA, 2010; Chumbler, Kobb, Brennan, \& Rabinowitz, 2008).

\section{RESULTS}

\section{RATE OF RETURN}

Of the 1,900 surveys that were sent to the ASHAcertified SLPs in the selected northeastern state, 170 were returned, a response rate of $9 \%$. Descriptive statistics were employed for items relating to respondent demographics, use of and knowledge and skills of SLPs' utilizing telepractice, and SLPs' attitudes toward telepractice. The most frequent responses and outlier comments were tabulated for the final four open-ended questions.

\section{RESPONDENT DEMOGRAPHICS}

Years of employment ranged from 1 to $25+$ years with the majority of survey respondents in the 25+ years category (43.53\%). Responses came from all four geographical regions across the state but predominantly from eastern (48.82\%) and southern (27.06\%) locations, with $21.76 \%$ from the west and $2.35 \%$ from the north. These regional percentages correlate with the current distribution of the population in this state. 


\section{TELEPRACTICE USAGE}

Survey Questions 4 - 14 pertained to knowledge, skills, and experiences of those SLPs who have provided telepractice in school settings. The use of telepractice in school settings in the northeastern state was reported by 10 SLPs out of the 170 respondents (6\%), with four reports of telepractice use outside the state. [Three of these SLPs were supervisors of telepractice programs and did not maintain a telepractice caseload. Two of these individuals worked in the western side of the state while one came from the eastern side.]

Seven SLPs provided telepractice, but four indicated that this was previous work and not current practice. Thus only three SLPs reported current provision of service via telepractice. All seven SLPs reported length of time, number of students, and percentage of work week devoted exclusively to telepractice. This varied from less than one year to more than three years in length, for one to up to 30 students. Telepractice service for all but one SLP involved less than $25 \%$ of their work week; one SLP reported $26-50 \%$ of the workweek for $11-20$ students.

\section{LOCATION OF TELEPRACTICE SERVICES}

The location of telepractice services, for both the students and the SLP delivering the therapy, was also reported. Telepractice delivery to students in an elementary school location was reported by all respondents, with middle through high school also listed for 5 of the 10. Three respondents indicated that they provided telepractice in a private or cyber school and two practiced in a special education center. The one SLP providing telepractice in the eastern region of the state delivered telepractice to students' homes. The most frequent SLP location from which to deliver telepractice was a special education center (five) with elementary school reported by four. The SLP in the southern part of the state was the only one who provided telepractice from home.

\section{SERVICE TYPES}

Seven SLPs and three SLP supervisors contributed data on the types of services provided via telepractice. The SLPs indicated which types of therapy services were provided, in terms of screening, assessment, treatment, and consultation. In addition, the three SLP supervisors who had experience with telepractice indicated that they had provided consultation and one provided assessment via telepractice. The SLPs with a current or past telepractice caseload indicated that the predominant service was treatment (85.7\%), followed by consultation (42.8\%), and screening (28.6\%). Similar to the SLP supervisor group, one treating SLP listed assessment as a service provided. One SLP specified consultation to teachers, parents, and others as the only telepractice service provided. The SLPs were also asked to indicate student areas of impairments from a non-inclusive list. The results revealed, in order of frequency served: Language Disorder (71.4\%); Articulation/Phonology (1\%); Fluency (28.6\%); with one each for Learning Disabilities; Autism Spectrum Disorders, and Attention Deficit (14.2\%).

The SLPs were questioned on what speech-language areas they believed were not appropriate for telepractice therapy, using the same list of non-inclusive areas. The results were mixed and are listed here in order of frequency of response: all areas are appropriate for telepractice (71.4\%); Birth to three, Dysphagia, or Motor Speech Disorders (57.1\%); Articulation/Phonology, Autism Spectrum Disorders, Fluency, or Preschool (42.8\%), Hearing Impairment, Mental Retardation, Psychiatric/ Emotional Disturbances, or Voice (28.6\%); Learning Disabilities (14.2\%).

\section{TELEPRACTICE ASSISTANTS}

The use of a telepractice assistant was reported in question 12. Three of the seven SLPs experienced in telepractice did not have a telepractice assistant. Four of the remaining experienced SLPs in this group indicated that the duties of these assistants included assisting students to remain on task and providing some degree of technology support. Three of the four revealed that the assistants communicated with teachers or other school staff, copied and/or collected materials, and helped get the students to and from class. One SLP reported the assistant, in addition to the aforementioned duties, attended Individualized Education Program (IEP) meetings and worked directly with students during therapy sessions.

\section{PRIOR TRAINING}

Training was questioned in items 13 and 14. First, the SLPs experienced in telepractice were asked to indicate their level of training regarding telepractice prior to implementing the service delivery model. Results as reported indicated that the majority of the SLPs (86.7\%) did receive some type of training in telepractice before initiating service. The final question asked of this group of SLPs experienced in telepractice was what type of additional training they felt they needed, if any. Results, as they were with responses for areas not suitable for telepractice, were mixed. Responses on prior training received and additional training desired are listed in Table 1. 
Table 1

Prior Training Received and Additional Training Desired

\begin{tabular}{|l|l|}
\hline Prior training & Additional training desired \\
\hline - On the job (5) & - None (4) \\
- Journals (3) & - Specific technology, \\
- Demonstration (1) & procedures, and student \\
- None (1) & selection criteria (3) \\
& - Specific technology and \\
& specific materials (1) \\
& - Student selection criteria (1) \\
\hline
\end{tabular}

Note. The corresponding numbers represent the number of SLP participants $(n=7)$ who selected the option; multiple options were selected by the same participants.

\section{ATtitudes TOWARd TElepractice}

The next section of the survey investigated all 170 SLP participants' attitudes toward telepractice using a 5 -point Likert scale with gradients from Strongly Agree through Strongly Disagree. Data from these questions revealed that statements to which the majority of the SLPs agreed were in the need for procedures and guidelines, confidentiality, informed consent, ethical considerations, technology procedures, and student selection criteria. Conversely, the greatest disagreements occurred with statements relating to telepractice assessment, establishment of rapport via telepractice, and effectiveness of telepractice as compared with inperson speech-language therapy. Essentially, the SLPs reported neutral attitudes toward an interest in providing telepractice in schools and in other settings. Data for these items are shown in Table 2. 


\begin{tabular}{|c|c|c|c|c|c|c|c|}
\hline Statement & M & SD & $\begin{array}{c}\text { Strongly } \\
\text { agree } \\
\mathrm{n} \\
\%\end{array}$ & $\begin{array}{r}\text { Agree } \\
\mathrm{n} \\
\%\end{array}$ & $\begin{array}{r}\text { Neutral } \\
\mathrm{n} \\
\%\end{array}$ & $\begin{array}{r}\text { Disagree } \\
n \\
\%\end{array}$ & $\begin{array}{r}\text { Strongly } \\
\text { disagree } \\
\mathrm{n} \\
\%\end{array}$ \\
\hline $\begin{array}{l}\text { 15. Specialized training will be needed by the } \\
\text { SLP to deliver telepractice services. }\end{array}$ & 2.11 & 1.11 & $\begin{array}{r}59 \\
34.7\end{array}$ & $\begin{array}{r}61 \\
35.9\end{array}$ & $\begin{array}{r}30 \\
17.6\end{array}$ & $\begin{array}{r}12 \\
7.1\end{array}$ & $\begin{array}{r}8 \\
4.7\end{array}$ \\
\hline $\begin{array}{l}\text { 16. Assessments can be completed as } \\
\text { accurately via speech-language telepractice } \\
\text { as compared to in-person assessments. }\end{array}$ & 3.89 & 1.07 & $\begin{array}{r}6 \\
3.5\end{array}$ & $\begin{array}{r}12 \\
7.1\end{array}$ & $\begin{array}{r}36 \\
21.2\end{array}$ & $\begin{array}{r}57 \\
33.5\end{array}$ & $\begin{array}{r}59 \\
34.7\end{array}$ \\
\hline $\begin{array}{l}\text { 17. A different set of materials will need to be } \\
\text { acquired to deliver speech-language } \\
\text { telepractice services. }\end{array}$ & 2.44 & 1.09 & $\begin{array}{r}34 \\
20.0\end{array}$ & $\begin{array}{r}65 \\
38.2\end{array}$ & $\begin{array}{r}43 \\
25.3\end{array}$ & 19 & $\begin{array}{r}9 \\
5.3\end{array}$ \\
\hline $\begin{array}{l}\text { 18. Rapport between SLP and SCHOOL } \\
\text { PERSONNEL can be established during } \\
\text { speech-language telepractice as strongly as } \\
\text { during in-person speech-language therapy }\end{array}$ & 3.68 & 1.16 & $\begin{array}{r}7 \\
4.1\end{array}$ & $\begin{array}{r}24 \\
14.1\end{array}$ & $\begin{array}{r}36 \\
21.2\end{array}$ & $\begin{array}{r}52 \\
30.6\end{array}$ & $\begin{array}{r}51 \\
30.0\end{array}$ \\
\hline $\begin{array}{l}\text { 19. Rapport between SLP and STUDENT can } \\
\text { be established during speech-language } \\
\text { telepractice as strongly as during in-person } \\
\text { speech-language therapy. }\end{array}$ & 3.79 & 1.08 & $\begin{array}{r}3 \\
1.8\end{array}$ & $\begin{array}{r}21 \\
12.4\end{array}$ & $\begin{array}{r}39 \\
22.9\end{array}$ & $\begin{array}{r}53 \\
31.2\end{array}$ & $\begin{array}{r}54 \\
31.8\end{array}$ \\
\hline $\begin{array}{l}\text { 20. It is important to meet the students in- } \\
\text { person at some point during the speech- } \\
\text { language telepractice program. }\end{array}$ & 1.75 & 1.18 & $\begin{array}{r}108 \\
63.5\end{array}$ & $\begin{array}{r}24 \\
14.1\end{array}$ & $\begin{array}{r}20 \\
11.8\end{array}$ & $\begin{array}{r}9 \\
5.3\end{array}$ & $\begin{array}{r}9 \\
5.3\end{array}$ \\
\hline $\begin{array}{l}\text { 22. Speech-language telepractice services } \\
\text { can be as effective, in terms of student } \\
\text { progress toward goals, as in-person therapy. }\end{array}$ & 3.20 & 1.14 & $\begin{array}{r}14 \\
8.2\end{array}$ & $\begin{array}{r}27 \\
15.9\end{array}$ & $\begin{array}{r}67 \\
39.4\end{array}$ & $\begin{array}{r}35 \\
20.6\end{array}$ & $\begin{array}{r}27 \\
15.9\end{array}$ \\
\hline $\begin{array}{l}\text { 23. A set of approved ethical guidelines } \\
\text { should be determined before the } \\
\text { implementation of any speech-language } \\
\text { telepractice program in the schools. }\end{array}$ & 1.42 & 0.88 & $\begin{array}{r}127 \\
74.7\end{array}$ & $\begin{array}{r}27 \\
15.9\end{array}$ & $\begin{array}{r}9 \\
5.3\end{array}$ & $\begin{array}{r}2 \\
1.2\end{array}$ & $\begin{array}{r}5 \\
2.9\end{array}$ \\
\hline $\begin{array}{l}\text { 24. Student and SLP confidentiality } \\
\text { guidelines, including archival procedures, } \\
\text { should be included in school speech- } \\
\text { language telepractice program guidelines. }\end{array}$ & 1.34 & 0.82 & $\begin{array}{r}135 \\
79.4\end{array}$ & $\begin{array}{r}24 \\
14.1\end{array}$ & $\begin{array}{r}5 \\
2.9\end{array}$ & $\begin{array}{r}1 \\
0.6\end{array}$ & $\begin{array}{r}5 \\
2.9\end{array}$ \\
\hline $\begin{array}{l}\text { 25. Informed consent procedures for all } \\
\text { participants should be included in school } \\
\text { speech-language telepractice programs. }\end{array}$ & 1.36 & 0.85 & $\begin{array}{r}134 \\
78.8\end{array}$ & $\begin{array}{r}22 \\
12.9\end{array}$ & $\begin{array}{r}8 \\
4.7\end{array}$ & $\begin{array}{r}1 \\
0.6\end{array}$ & $\begin{array}{r}5 \\
2.9\end{array}$ \\
\hline $\begin{array}{l}\text { 26. Licensure laws should allow for } \\
\text { reciprocity between states for school speech- } \\
\text { language telepractice purposes. }\end{array}$ & 2.04 & 1.24 & $\begin{array}{r}80 \\
47.1\end{array}$ & $\begin{array}{r}41 \\
24.1\end{array}$ & $\begin{array}{r}24 \\
14.1\end{array}$ & $\begin{array}{r}12 \\
7.1\end{array}$ & $\begin{array}{r}13 \\
7.6\end{array}$ \\
\hline $\begin{array}{l}\text { 27. Minimum technology standards should be } \\
\text { included in school speech-language } \\
\text { telepractice program guidelines. }\end{array}$ & 1.99 & 1.23 & $\begin{array}{r}83 \\
48.8\end{array}$ & $\begin{array}{l}39 \\
22 .\end{array}$ & $\begin{array}{r}25 \\
14.7\end{array}$ & $\begin{array}{r}12 \\
7.1\end{array}$ & $\begin{array}{r}11 \\
6.5\end{array}$ \\
\hline $\begin{array}{l}\text { 28. Procedures to follow in the presence of } \\
\text { technology failures should be included in } \\
\text { school speech-language telepractice } \\
\text { programs. }\end{array}$ & 1.45 & 0.86 & $\begin{array}{r}120 \\
70.6\end{array}$ & $\begin{array}{r}35 \\
20.6\end{array}$ & $\begin{array}{r}9 \\
5.3\end{array}$ & $\begin{array}{r}1 \\
0.6\end{array}$ & $\begin{array}{r}5 \\
2.9\end{array}$ \\
\hline $\begin{array}{l}\text { 29. Student selection criteria should be } \\
\text { included in school speech-language } \\
\text { telepractice program guidelines. }\end{array}$ & 1.54 & 0.96 & $\begin{array}{r}113 \\
66.5\end{array}$ & $\begin{array}{r}38 \\
22.4\end{array}$ & $\begin{array}{r}9 \\
5.3\end{array}$ & $\begin{array}{r}4 \\
2.4\end{array}$ & $\begin{array}{r}6 \\
3.5\end{array}$ \\
\hline $\begin{array}{l}\text { 30. I would be interested in providing speech- } \\
\text { language pathology services via telepractice } \\
\text { in SCHOOL settings. }\end{array}$ & 3.25 & 1.35 & $\begin{array}{r}21 \\
12.4\end{array}$ & $\begin{array}{r}32 \\
18.8\end{array}$ & $\begin{array}{r}45 \\
26.5\end{array}$ & $\begin{array}{r}28 \\
16.5\end{array}$ & $\begin{array}{r}44 \\
25.9\end{array}$ \\
\hline $\begin{array}{l}\text { 31. I would be interested in providing speech- } \\
\text { language pathology services via telepractice } \\
\text { in OTHER settings besides schools. }\end{array}$ & 3.24 & 1.37 & $\begin{array}{r}23 \\
13.5\end{array}$ & $\begin{array}{r}31 \\
18.2\end{array}$ & $\begin{array}{r}41 \\
24.1\end{array}$ & $\begin{array}{r}32 \\
18.8\end{array}$ & $\begin{array}{r}43 \\
25.3\end{array}$ \\
\hline
\end{tabular}

Table 2

Data for Statements Targeting SLPs' Attitudes toward Telepractice

Question 21 requested SLPs to provide their beliefs regarding when in-person meetings should occur, with choices provided as: assessment, monthly, midschool year, dismissal, or do not need to meet. A field for other suggestions was also provided. Responses were compared between those SLPs with prior telepractice experience $(n=14)$ and those without experience $(n=156)$. These results indicate that assessment is preferred by more than half of the respondents to be conducted onsite. More than a quarter of the SLPs feel that there should be an onsite visit monthly. While $14 \%$ of SLPs with telepractice experience believed that no meeting is necessary, only $6 \%$ of SLPs without telepractice experience thought similarly, a difference of greater than half. Comments that did not fit the categories or combination of categories, in order of decreasing frequency, included: depends on client (4 responses), as often as possible (3), weekly or biweekly (3), do not believe in telepractice (3), and prior to assessment (1).

Additional analysis of results to Statement 30 regarding level of interest in providing telepractice in school settings was conducted to compare responses of those SLPS experienced versus not experienced in telepractice. The graph in the following figure reveals this comparison of interest. 
Figure 1. Comparison of Interest in Telepractice in School Settings.

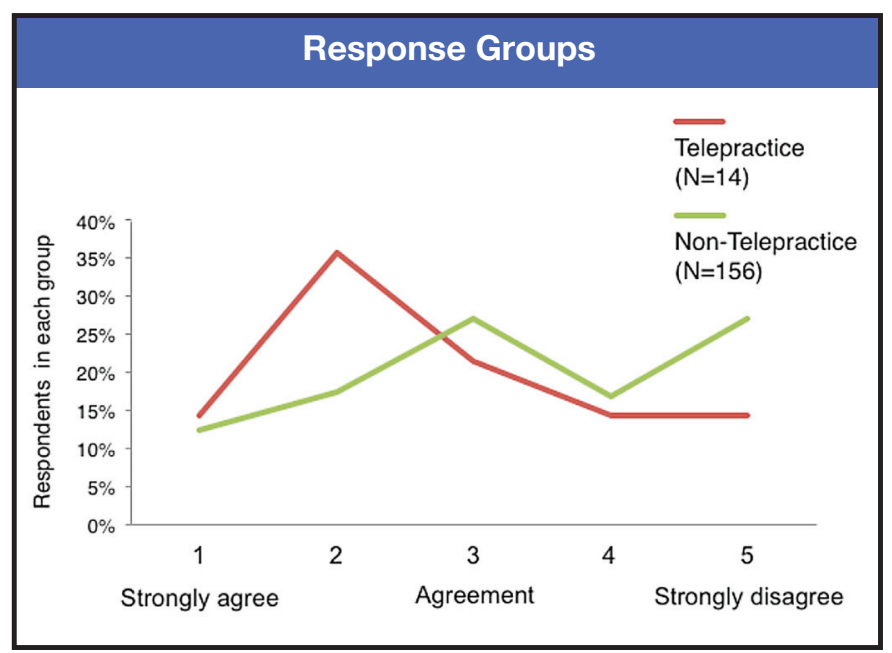

\section{CLINICIAN EXPERIENCE}

Responses by SLPs with greater than 25 years experience in the field of speech-language pathology were compared to those SLPs with less than five years experience for Statements 30 and 31. Table 3 displays those results. Additionally, SLPs experienced in telepractice delivery responded to these same interest statements with averages of 2.79 and 2.71, respectively, which may indicate an interest in telepractice approximately equal to those SLPs with 1-5 years experience in the field. Caution must be exercised in viewing these results due to the small sample sizes.

Table 3

\section{Averages for Attitudinal Statements 30 \& 31}

\begin{tabular}{|c|c|c|}
\hline \multicolumn{3}{|c|}{ Averages for Attitudinal Statements 30 \& 31} \\
\hline $\begin{array}{l}\text { Interest in providing } \\
\text { Telepractice }\end{array}$ & $\begin{array}{l}\text { SLPs 25+ } \\
\text { years } \\
(n=74)\end{array}$ & $\begin{array}{l}\text { SLPs with } \\
1-5 \text { years } \\
(\mathrm{n}=17)\end{array}$ \\
\hline In school settings & 3.40 & 2.70 \\
\hline In other settings & 3.32 & 2.53 \\
\hline
\end{tabular}

Note. Scale of 1 Strongly agree to 5 Strongly disagree.

\section{REASONS TO USE/NOT USE TELEPRACTICE}

The final four items of the survey were open-ended to elicit individual comments that might allow for additional expression of attitudes and beliefs about telepractice. For Questions 32 and 33 all 170 of the SLPs were invited to provide reasons for and against the use of telepractice in school settings. The comments were reviewed, sorted, and counted by the frequency of terms in answers. The most frequent responses by the SLPs cited student reasons for both categories. There were no reasons to use telepractice for 15 SLPs, while only two SLPs indicated there were no reasons not to use it. There were more reasons not to use than to use telepractice. These responses are shown in Table 4. 
Table 4

Reasons to Use and Not to Use Telepractice in School

\begin{tabular}{|l|l|l|l|}
\hline Reasons to use telepractice & $\mathbf{n}$ & Reasons not to use telepractice & $\mathbf{n}$ \\
\hline Student Benefit & 54 & Student Type/Age & 54 \\
Rural or other location & 54 & Impersonal & 53 \\
Cost of travel/time & 33 & Lack of Physical Contact & 24 \\
Ease SLP Shortage & 30 & Effectiveness & 23 \\
Collaboration & 19 & Technology standards or failures & 18 \\
No reason to use it & 15 & Lack of collaboration & 15 \\
Benefits for SLPs & 3 & Cost & 15 \\
Benefits for Families & 1 & Ethical concerns & 11 \\
& & Lack of support & 8 \\
& & Lack of standardized assessments & 4 \\
& & Lack of training of SLPs & 3 \\
\end{tabular}

SLPs offered insightful comments for these questions. Under reasons to use speech-language telepractice services in schools, one SLP wrote, "I feel that SLP telepractice should ONLY be used in cases where NO in-person SLP services are possible." Another SLP revealed that she felt it could be a useful tool "in light of recent flooding and tornadoes in the south and west in this country. School services could perhaps be resumed more quickly through the use of central locations where telepractice connections could be arranged." One SLP indicated that telepractice could be used to "supervise/ guide speech-language assistants." A human connection was the focus for several SLPs as reasons not to use telepractice. Examples included: "We spend our entire time trying to teach children to communicate effectively person-to-person. Telepractice has no place in this paradigm;" "We are losing the positive benefits of human interaction - face to face - human contact;" "The art of communication can never be replaced with technology."

Finally, the survey probed for additional comments regarding speech-language telepractice as a service delivery model in school settings and in other settings. Out of the 56 comments that were provided regarding telepractice in school settings, 18 individuals felt that it was inappropriate while 11 thought it was a good idea with another eight focusing on telepractice as a good tool for working with students. Eleven SLPs felt that guidelines and support were needed to implement telepractice, but eight SLPs indicated that they did not feel they had enough knowledge about it to comment. Discussing the use of telepractice in other settings, 33 comments were generated with eight SLPs stating affirmation of use and seven against it. Ten SLPs thought telepractice could be a good application for therapy with the adult population, but four revealed that more support would be needed for a viable telepractice program. In the other settings, one SLP remarked that she "would like to see telepractice being utilized in hospital and nursing home settings to ensure all patients have access to entire SLP scope of practice services." Another quote of an affirmative nature was "I think this is a positive step in the right direction given all the advancements in technology," while another SLP countered, "I am opposed to the idea anywhere. We're already becoming a world relying too much on communication without personal contact, thus creating a generation with limited speaking experience." These responses were found to be similar to those generated for reasons to and not to use telepractice, and will be further elaborated in the discussion section. Overall, there were more negative remarks (29) than positive ones (19) for use of telepractice in schools, and more positive (19) than negative (11) comments for telepractice use in other settings. 


\section{COMPARISON TO THE ASHA} (2002) STUDY

Comparisons of the results of the current survey, and selected portions of the ASHA 2002 telepractice survey revealed few similarities. Caution must be exercised in comparing these two studies due to differing populations and geographical locations, size of samples, and questions posed.

\section{USE OF TELEPRACTICE}

The survey results reported upon in the current survey could be interpreted to conclude that the major barriers to telepractice utilization are the need for procedures and guidelines, concerns for lack of confidentiality and other ethical considerations, and student selection criteria. However, factors beyond the scope of decision making for the practicing SLP must be considered. Decisions regarding telepractice made at the administrative level, including budget allocation for equipment and personnel, have significant impact on barriers and incidence of telepractice. In comparison, ASHA's 2002 survey reported that $11 \%$ of 1667 SLP and audiologist respondents had used telepractice. ASHA's researchers concluded that barriers to telepractice utilization for its members included lack of knowledge, concerns regarding applicability to certain groups of patients, cost, and lack of professional standards.

\section{DISORDER TYPE}

Respondents of both surveys served individuals with motor speech disorders including articulation/ phonological impairments. Not surprisingly, the schoolbased SLPs served more clients with language disorders (71\%) than the SLPs and audiologists in the ASHA 2002 survey (42\%). It could be inferred from these results that the telepractice programs in both studies mirrored traditional therapy that would have been provided by these two groups of practitioners in terms of types of communication disorders and clients served.

\section{TRAINING}

Twenty-one percent of the telepractice users in the ASHA 2002 survey had received previous education or training, with the majority (47\%) learning on the job. In comparison, $86 \%$ of the telepractice users from the 2011 survey had received prior training; most received on the job training. The SLPs in the current study did not feel that they needed specialized training on telepractice technology but rather that specific guidelines and procedures should be established by the speechlanguage pathology profession. It could be speculated that improvements in the technology itself has caused this shift over the past 9 years from a focus on the technology to one that is student-centered and procedure-centered.

\section{INTEREST IN SERVICE PROVISION}

In the ASHA 2002 survey, 43\% expressed an interest in using telepractice in the future. In the subsequent ASHA (2011) survey only $32 \%$ of the SLP participants expressed interest in providing telepractice services. When comparing these studies with previous research, it appears that the SLPs continue to reflect and question how best to serve their students regardless of service delivery model.

\section{POSSIBLE TRENDS}

\section{INTEREST}

A possible trend was noted regarding interest in providing future telepractice services between those SLPs who had experience in telepractice versus those who had not. Not surprisingly, those SLPs who had experience in telepractice were more inclined to express interest in this type of service. The graph in Figure 2 reveals this comparison. It may be surmised that awareness, actual exposure, and confidence led to a willingness to participate in future telepractice situations. Discussions and networking among these two groups of SLPs may help to dispel apprehension toward this emerging form of service delivery and increase acceptance and trust (Buck, 2008; Dunkley, Pattie, Wilson, \& McAllister, 2010; Whitten \& Love, 2005).

\section{Clinician Age}

Another trend was a stronger interest in providing telepractice by younger SLPs, (i.e., those with less experience in the field of speech-language pathology). These responses may reveal that more experienced SLPs are less interested in pursuing this new form of service delivery than those newer to the field of speech-language pathology. If so, exposure and instruction to telepractice services at the graduate level may help speed SLPs' acceptance, confidence, and utilization of this emerging form of service delivery. Another conclusion, however, could be that younger SLPs are simply more familiar with technology, and as such, would make better candidates for trying and using telepractice services than veteran SLPs. Interpretation of the results across the spectrum of all experience levels appears to indicate that the majority 
of SLPs in this northeastern state are undecided or not highly interested in pursuing the use of telepractice.

\section{PERCEIVED BENEFITS}

The SLPs listed advantages for students (e.g., improved access; specialists with expertise to match speech disorder needs; appropriate frequency of services due to improved access, etc.) as their top reason for use of telepractice. Concern about meeting the needs of students was listed as the most significant barrier.

\section{PERCEIVED CONTRAINDICATIONS}

More reasons not to use telepractice $(n=12)$ were generated than reasons to use telepractice $(n=7)$ in school settings. Approximately $25 \%$ of the 170 respondent SLPs noted that they were unsure or undecided about telepractice, with the rest of the group slightly less interested (44\%) than in favor (31\%) of the use of telepractice in school settings. The impersonal nature of telepractice including the lack of human touch appears to be a barrier to acceptance of a telepractice service delivery model by the typical SLP who may build relationships with educators through common activities within the school building. There appears to be professional skepticism about using telepractice to administer assessments via telepractice. From these results, it appears that there is uncertainty about the outcomes associated with the use of telepractice, especially for particular students who may have more complex therapeutic needs. The SLPs also questioned the ability to establish rapport when services were provided at a distance via telepractice. Continued research into human dynamics, student candidacy, and profession-specific guidelines should assist in providing the clarity that these SLPs appear to require before demonstrating readiness and willingness to accept the use of telepractice in speech-language pathology.

\section{CONCLUSIONS}

Limitations to the current research include a small sample size and representation from only one state.

Review of the overarching results of the quantitative survey in this study of 170 SLPs indicated reticent or outright resistance toward practicing speech-language pathology through telepractice. This group of respondents offered essentially neutral or negative attitudes about the telepractice environment, the possibility of establishing rapport with clients, and the likelihood of effective outcomes.

The current usage level of telepractice by $1.8 \%$ of the responding SLPs demonstrates that few SLPs who responded to the survey have provided or have continued to provide telepractice services. Factors that could be contributing to this small utilization of telepractice include: age of respondent SLPs, lack of interest in exploring technological options, the current budgetary constraints for funding technology in schools, and administrator interest and attitudes toward telepractice (an area for future research).

In the present study, only the less experienced SLPS, who are presumably younger than the more experienced SLPs who have been practicing longer, and those SLPs who have telepractice experience indicated willingness to use telepractice. Perhaps these results reveal that younger SLPs, more accustomed to using technology, are ready to engage in telepractice.

Further comparative studies on this topic may shed light on the continuing trend of limited acceptance and use of telepractice in speech-language pathology. Since several of the SLPs in this portion of the study indicated that they no longer provided clinical services via telepractice, another valuable line of inquiry would pertain to the reasons for the lack of continuance. 


\section{REFERENCES}

1. Alverson, D., Holtz, B., D’lorio, J., DeVany, M., Simmons, S., \& Poropatich, R. K. (2008). One size doesn't fit all: Bringing telehealth services to special populations. Telemedicine and e-Health, 14, 957- 963. doi: 10.1089/ tmj.2008.0115

2. American Speech-Language-Hearing Association. (2002). Survey report on telepractice use among audiologists and speech-language pathologists. Retrieved from http://www.asha.org/policy

3. American Speech-Language-Hearing Association. (2005a). Knowledge and skills needed by speechlanguage pathologists providing clinical services via telepractice. doi: 10.1044/policy.KS2005-00077. Retrieved from http://www.asha.org/policy/KS200500077.htm

4. American Speech-Language-Hearing Association. (2005b). Speech-language pathologists providing clinical services via telepractice: Position statement. Retrieved from http://www.asha.org/policy/PS2005-00116.htm

5. American Speech-Language-Hearing Association. (2005c). Speech-language pathologists providing clinical services via telepractice: Technical report. doi: 10.1044/ policy.TR2005-00152. Retrieved from http://www.asha. org/docs/html/TR2005-00152.html

6. American Speech-Language-Hearing Association. (2010). Professional issues in telepractice for speechlanguage pathologists. doi:10.1044/policy.PI2010-00315. Retrieved from http://www.asha.org/policy/PI201000315.htm

7. American Speech-Language-Hearing Association. (2011). 2011 Membership survey: CCC-SLP survey summary report: Number and type of responses. Retrieved from http://www.asha.org/uploadedFiles/2011Membership-Survey-CCC-SLP-Summary-Report.pdf

8. Benefield, N., \& Runk, J. (2008). A primer on Pennsylvania Cyber Schools. Retrieved from http://www. uscharterschools.org/cs/r/lpt/uscs_rs/2421

9. Brady, A. (2007). Moving toward the future: Providing speech-language pathology services via telehealth. Home Healthcare Nurse, 25, 240-244.

10. Brown, J. (2009). Telepractice: The next generation. Presentation at Texas Speech-Language-Hearing Association (TSHA) Annual Convention. Retrieved from http://www.txsha.org/_pdf/Convention/09Convention/ New\%20Folder/Brown,\%20Janet-Telepractice_The\%20 Next\%20Generation.pdf

11. Buck, S. (2009). Nine human factors contributing to the user acceptance of telemedicine applications: A cognitive-emotional approach. Journal of Telemedicine and Telecare, 15, 55-58. doi: 10.1258/jtt.2008.008007

12. Bulik, R. J. (2008). Human factors in primary care telemedicine encounters. Journal of Telemedicine and Telecare, 14, 169-172. doi: 10.1258/jtt.2007.007041

13. Chumbler, N. R., Kobb, R., Brennan, D. M., \& Rabinowitz, T. (2008). Recommendations for research design of telehealth studies. Telemedicine and e-Health, 14, 986989. doi: 10.1089/tmj.2008.0108

14. Creswell, J. W. (2008). Educational research: Planning, conducting, and evaluating quantitative and qualitative research (3rd ed.). Upper Saddle River, NJ: Pearson Publishing.
15. Creswell, J. W., \& Plano-Clark, V. L. (2011). Designing and conducting mixed methods research. Thousand Oaks, CA: Sage Publications, Inc.

16. Dunkley, C., Pattie, L., Wilson, L., \& McAllister, L. (2010). A comparison of rural speech-language pathologists' and residents' access to and attitudes towards the use of technology for speech-language pathology service delivery. International Journal of Speech-Language Pathology, 12, 333-343. doi: 10.3109/17549500903456607

17. Fink, A. (2003). The survey kit (2nd ed.).Thousand Oaks, CA: Sage Publications.

18. Hill, A. J., Theodoros, D. G., Russell, T. F., Cahill, L. M., Ward, E. C., \& Clark, K. M. (2006). An Internetbased telerehabilitation system for the assessment of motor speech disorders: A pilot study. American Journal of Speech-Language Pathology, 15, 45-56. doi: 10.1044/1058-0360(2006/006)

19. Hill, A., \& Theodoros, D. (2002). Research into telehealth applications in speech-language pathology. Journal of Telemedicine and Telecare, 8, 187-196. Retrieved from http://web.ebscohost.com.ezproxy.ycp.edu:8000/ehost/ pdfviewer/pdfviewer?vid=4\&hid=6\&sid=ae1dc4fc-7f74422b-b0a5-1b7884666ec7\%40sessionmgr113

20. Houn, B., \& Trottier, K. (2006, November 13). Meeting the challenge of rural service delivery. The ASHA Leader Online. Retrieved from http://www.asha.org/practice/ telepractice/TelepracticeReferences.htm

21. Juenger, J. M. (2009a, July). Telepractice in speech/ language: How to get there from here. Session presented at the American Speech-Language-Hearing Association (ASHA) Schools Conference, Kansas City, MS.

22. Juenger, J. M. (2009b, September 22). Telepractice in the schools. The ASHA Leader, 14(12), 20-21.

23. Kelso, G. L., Fiechtl, B. J., Olsen, S. T., \& Rule, S. (2009). The feasibility of virtual home visits to provide early intervention. Infants \& Young Children, 22, 332-340.

24. Mashima, P. A., \& Doarn, C. R., (2008). Overview of telehealth activities in speech-language pathology. Telemedicine and e-Health, 14, 1101-1117. doi: 10.1089/ tmj. 2008.0080

25. Meline, T. (2006). Research in communication science and disorders. Upper Saddle River, NJ: Pearson Education, Inc.

26. Müller, E. (2009). Serving students with disabilities in state-level virtual K-12 public school programs. Retrieved from Project Forum National Association of State Directors of Special Education (NASDSE) website: http://www.projectforum.org/docs/Serv ingStudentswithDisabilitiesinState-levelVirtualK12PublicSchoolPrograms.pdf

27. National Center for Education Statistics. (2008). Number of full-time and part-time public school staff, by type of staff and state: 2007-08. Retrieved from http://nces. ed.gov/surveys/sass/tables/sass0708_2009321_s1s_05. asp

28. Polovoy, C. (2008, July 15). Telepractice in schools helps address personnel shortages. The ASHA Leader, 13(9), 22-24. 
29. Theodoros, D. G., (2008). Telerehabilitation for service delivery in speech-language pathology. Journal of Telemedicine and Telecare, 14, 221-224. doi: 10.1258/ jtt.2007.007044

30. Torrens, J. (2004). Utilization and reimbursement of telepractice among speech-language pathologists in upstate New York hospitals. Retrieved from ProQuest Dissertations and Theses database. (UMI No. 3118195)

31. Whitten, P., \& Love, B. (2005). Patient and provider satisfaction with the use of telemedicine: Overview and rationale for cautious enthusiasm. Journal of Postgraduate Medicine, 51, 294-300.

32. Whitten, P., \& Holtz, B. (2008a). A series of papers for those yearning to propel telehealth to new heights. Telemedicine and e-Health, 14, 952-956. doi: 10.1089/ tmj.2008.0129

33. Whitten, P., \& Holtz, B. (2008b). Provider utilization of telemedicine: The elephant in the room. Telemedicine and e-Health, 14, 995-997. doi: 10.1089/tmj.2008.0126 
